\title{
Short-term effects of flooding on bacterial community structure and nitrogenase activity in microbial mats from a desert stream
}

\author{
Raeid M. M. Abed ${ }^{1, *}$, Sumaiya Al Kindi ${ }^{1}$, Angela Schramm ${ }^{2}$, Michael J. Barry ${ }^{1}$ \\ ${ }^{1}$ Sultan Qaboos University, College of Science, Biology Department, PO Box 36, Al Khoud, 123 Muscat, Sultanate of Oman \\ ${ }^{2}$ Max-Planck Institute for Marine Microbiology, Celsiusstraße 1, 28359 Bremen, Germany
}

\begin{abstract}
Flood-induced disturbance causes major shifts in the diversity and function of microbial communities in desert streams. We compared bacterial community structure (using automated rRNA intergenic spacer analysis, ARISA), pigment composition and nitrogen fixation rates in benthic microbial mats from stone surfaces collected from 6 sites along a desert stream in the Sultanate of Oman before and $2 \mathrm{wk}$ after an intense flood. Flooding caused partial flushing out of old mats, and new mats re-established on the surfaces of rocks. Visually, the filamentous green algae Spirogyra spp. increased in abundance in the water column at most sites after the flood, and direct microscopy revealed that the newly developed mats were dominated by the heterocystous Calothrix spp. Multivariate analyses of ARISA profiles revealed that, in each mat, the structure of the bacterial community was different after the flood (analysis of similarities [ANOSIM], $R=0.49, \mathrm{p}<0.001$ ), and pairwise comparison of the presence/absence of operational taxonomic units (OTUs) showed that only between 18 and $26 \%$ shared OTUs. The OTU richness in the newly developed microbial communities decreased in 6 mats after the flood, but remained similar or slightly increased in the other 6 mats. Out of the 9 detected pigments, chlorophyll $a$, scytonemin, fucoxanthin, diadinoxanthin and $\beta$ carotene showed site-specific changes with flooding. The average acetylene reduction rates increased after the flood at all sites; however, this increase was statistically significant at only 2 sites due to the high variance among samples. In conclusion, flooding resulted in the replacement of over $74 \%$ of the microbial communities within mats, while nitrogen fixation rates remained stable or increased.
\end{abstract}

KEY WORDS: Microbial mats $\cdot$ Flooding $\cdot$ ARISA $\cdot$ Acetylene reduction rate $\cdot$ Pigments $\cdot$ Nitrogen fixation

Resale or republication not permitted without written consent of the publisher

\section{INTRODUCTION}

Desert streams are the arteries of the arid zone (Bunn et al. 2006b), essential for ecological, agricultural and social systems. Although varying greatly in their physical, chemical and biological parameters, they display many common characteristics that distinguish them from their temperate counterparts. On average, irradiance levels are higher, maximum temperatures are greater, and the stream flow is more variable (Bunn et al. 2006a). The benthic periphyton communities of desert streams are frequently dominated by cyanobacteria (Grimm \& Petrone 1997), often in the form of dense microbial mats. The presence of heterocystous types can be of great importance for the nitrogen supply of the ecosystem (Grimm \& Petrone 1997); nitrogen is potentially a limiting nutrient in arid streams (Grimm \& Fisher 1986b, Elser et al. 1990). Much of our knowledge of desert streams comes from a limited number of locations in southwestern USA and dryland regions of Africa (Grimm \& Fisher 1986a, Grimm \& Petrone 1997, Bunn et al. 2006a). The aridregion streams of Arabia, frequently referred to as wadis, represent poorly studied but important ecosys- 
tems. As arid-zone streams face many stresses, both natural and anthropogenic (Ormerod et al. 2010), ecological studies on these systems can contribute significantly to the development of effective management systems and to our understanding of processes in aridregion streams in general.

Benthic communities in desert streams are shaped and constrained by their extreme physical environment, in particular, unpredictable and flashy flows (Fisher et al. 1982). The most predictable effects of high-flow events are scouring of rocks and sediments, resulting in the removal of a substantial amount of their periphytic biomass, and the generation of spatial patchiness in biodiversity (Power \& Stewart 1987, Peterson et al. 1994, Augspurger et al. 2010). The flood water may carry high levels of nutrients (Grimm \& Petrone 1997), and detached microbial cells may migrate and recolonize elsewhere (Hamilton \& Duthie 1987, Biggs \& Close 1989). Therefore, floods have been identified as a major mechanism for resetting community dynamics and initiating new cycles of structural and metabolic succession (Fisher et al. 1982). Despite numerous studies on the effects of flooding on lotic ecosystems, which focused mainly on nutrient distribution and algal recovery (Fisher et al. 1982, Power \& Stewart 1987, Biggs \& Close 1989, McDiffett et al. 1989, Stevenson 1990), relatively little research has been performed to measure changes in the diversity of bacterial communities within microbial mats and the effects of flooding on functional traits of microorganisms, such as nitrogen fixation. However, several recent studies have examined the relationship between flow and the microbial structure of river biofilms (Besemer et al. 2009, Boulêtreau et al. 2010).

The short-term (i.e. $2 \mathrm{wk}$ ) effects of a flood-induced disturbance on benthic microbial communities from 6 sites in a single desert stream in northern Oman were studied in order to find out: (1) how flooding affects the structure of benthic microbial communities directly after the flood, (2) whether these communities persist after the flood or become redistributed by scouring, and (3) how flooding affects the rates of microbial nitrogen fixation. The structure of microbial communities, and nitrogenase activities, before and after the flood were compared using automated rRNA intergenic spacer analysis (ARISA), high-performance liquid chromatography (HPLC) pigment analysis, and the acetylene-reduction assay, respectively.

\section{MATERIALS AND METHODS}

Study site and collection of samples. All samples were collected from Wadi Al-Khoud, located near Muscat, northern Oman. The wadi is typical of many desert streams in the region in that it has a mosaic of habitats, some connected to the main channel and others isolated. The average annual rainfall in the region is $86 \mathrm{~mm}$, but this can vary widely (Fischer \& Membery 1998). The recorded air temperature ranges from 10 to $50^{\circ} \mathrm{C}$, with an average of $28.7^{\circ} \mathrm{C}$ (Fischer \& Membery 1998). Following a preliminary survey, 6 sites along the wadi were selected on the basis of observed variations in their texture, surface colour and surface growth of local microbial mats (Table 1). The sites were numbered sequentially from 1 to 6 , with Site 1 being the most downstream. All sites were less than $40 \mathrm{~cm}$ deep and had a current velocity ranging from $<1$ to $50 \mathrm{~cm} \mathrm{~s}^{-1}$ (Table 1). Site 5 was an isolated pool with no detectable flow, about $3 \mathrm{~m}$ from the main channel, while Site 6 was very broad, with a maximum width of ca. $8 \mathrm{~m}$ and was very slow-moving. The salinity at all sites was $1 \%$ or less, with neutral $\mathrm{pH}$, and the water temperature ranged between 24 and $31^{\circ} \mathrm{C}$. Dissolved

Table 1. Characteristics of the 6 studied sites in the Wadi Al Khoud desert stream, Oman, based on a preliminary survey of the region before flooding. ++ : abundant ${ }_{i}+$ : $_{\text {rare }}$-: absent

\begin{tabular}{|c|c|c|c|c|c|c|}
\hline Parameters & Site 1 & Site 2 & Site 3 & Site 4 & Site 5 & Site 6 \\
\hline \multirow{2}{*}{ Location } & $23^{\circ} 34.423^{\prime} \mathrm{N}$ & $23^{\circ} 34.262^{\prime} \mathrm{N}$ & $23^{\circ} 33.309^{\prime} \mathrm{N}$ & $23^{\circ} 33.105^{\prime} \mathrm{N}$ & $23^{\circ} 32.377^{\prime} \mathrm{N}$ & $23^{\circ} 32.377^{\prime} \mathrm{N}$ \\
\hline & $58^{\circ} 07.080^{\prime} \mathrm{E}$ & $58^{\circ} 07.017^{\prime} \mathrm{E}$ & $58^{\circ} 06.263^{\prime} \mathrm{E}$ & $58^{\circ} 06.265^{\prime} \mathrm{E}$ & $58^{\circ} 05.923^{\prime} \mathrm{E}$ & $58^{\circ} 05.921^{\prime} \mathrm{E}$ \\
\hline Temperature $\left({ }^{\circ} \mathrm{C}\right)$ & 31.0 & 29.0 & 26.5 & 24.2 & 24.3 & 24.6 \\
\hline Salinity (\%) & 1.0 & 0.5 & 1.0 & 1.0 & 1.0 & 1.0 \\
\hline Depth $(\mathrm{cm})$ & 10.0 & 49.0 & 12.0 & 12.0 & 40.0 & 40.0 \\
\hline Current velocity $\left(\mathrm{cm} \mathrm{s}^{-1}\right)$ & 3.8 & 25.0 & 5.5 & 50.0 & 0.0 & 0.0 \\
\hline $\mathrm{pH}$ & 7.1 & 7.2 & 7.6 & 7.2 & 7.5 & 7.7 \\
\hline Oxygen $\left(\mathrm{mg} \mathrm{l}^{-1}\right)$ & 6.5 & 8.8 & 15.5 & 15.1 & 14.5 & 14.5 \\
\hline Growth of microbial mats & On rocks & On rocks & On rocks & On rocks & On sediment & $\begin{array}{c}\text { Balls } \\
\text { on sediment }\end{array}$ \\
\hline Surface colour of mats & Brown/orange & Brown/green & Brown/orange & Brown/green & Green/white & Green/brown \\
\hline Floating algae & ++ & ++ & + & ++ & + & + \\
\hline Fish & ++ & ++ & ++ & + & ++ & ++ \\
\hline Presence of trees & - & - & ++ & ++ & + & + \\
\hline
\end{tabular}


oxygen in the water varied between 6 and $15 \mathrm{mg} \mathrm{l}^{-1}$ (Table 1), with the lowest oxygen concentrations at Sites 1 and 2, where temperatures were highest. All sites contained native fish (Aphnias dispar or Garra barreimiae) as well as introduced Tilapia spp. Sites 1 and 2 contained emergent stands of macrophytes dominated by Schenoplectus littoralis, while Sites 3 and 4 had thick riparian vegetation on 1 side dominated by the invasive tree Prosopis juliflora.

Microbial mats were collected in duplicates (designated $A$ and B) from the 6 studied sites along the main stream channel before the spate (November 2008) and 2 wk afterwards. Rainfall commenced on 31 March 2009 and lasted $\sim 24 \mathrm{~h}$. The mats at Sites 1 to 4 varied in colour (Table 1) and were dominated by pebbles and small cobbles, although sandy patches were found towards the edges. The mats at Site 5 were greenish, and loosely attached to the sediment below, at the edges of the pond. At Site 6, the mats were in fact discrete round balls, 1 to $10 \mathrm{~cm}$ in diameter, which moved through the loose flocculated sediment that covered the bottom. All the mats were submerged. Mat samples for DNA extraction and pigment analysis were stored at $-20^{\circ} \mathrm{C}$, whereas fresh samples were used for measurements of nitrogen fixation. Water samples were collected for the analysis of phosphate and ammonia using ion chromatography-Dionex IC 2000 and Kjeltec 2300 instruments, respectively.

Analysis of bacterial communities. The persistence and development of the benthic mat cyanobacteria (and also floating algae) in the studied sites after flooding were primarily assessed by field visual inspection as well as by direct microscopy. Pieces of mat were torn apart, mounted in water on a glass slide, and observed using transmitted light, phase-contrast and fluorescence microscopy. The bacterial communities in the studied microbial mats before and after flooding were further investigated using the ARISA technique. Triplicate mat samples of ca. 300 to $500 \mathrm{mg}$ were scraped off the stones (see Fig. 1), using a sterile blade, and were subjected to DNA extraction using the UltraClean soil DNA isolation kit (MO BIO Laboratories) according to the manufacturer's instructions.

PCR amplification was performed in triplicate for each replicate mat sample, with the same amounts of DNA (quantified by Nanodrop, Thermo Scientific) using the universal primer ITSF and the FAM-labelled eubacterial ITSReub primer (Cardinale et al. 2004) at an annealing temperature of $55^{\circ} \mathrm{C}$. The PCR products were purified using Sephadex G-50 Superfine (Sigma-Aldrich). DNA (150 ng) was then mixed with $0.5 \mu \mathrm{l}$ of internal size standard MapMarker ${ }^{\circledR} 1000$ ROX (50-1000 bp; BioVentures) and the amplified fragments were discriminated by capillary electrophoresis on an ABI PRISM 3130xl Genetic Analyzer (Applied Biosystems).
The ARISA profiles were analyzed using the GeneMapper software v 3.7 (Applied Biosystems). The total peak area per sample was normalized to 1 , and only those fragments between 100 and 1000 bp were considered. A 'fixed window' binning strategy with a bin size of $2 \mathrm{bp}$ was applied to the ARISA data (Böer et al. 2009), and the binning frame that offered the highest pairwise similarities among samples was subjected to multivariate analyses (see 'Statistical analysis' below). An operational taxonomic unit (OTU) was considered present in a given sample only if detected at least twice among the 3 replicated PCRs from the DNA extracts of that particular sample (Böer et al. 2009).

Pigment analysis. Pigment analysis gives an overview of coarse changes in the relative abundance of the major classes of phototrophs. It was performed in order to find out how flooding affects the phototrophic community of the microbial mats. The top 2 to $3 \mathrm{~mm}$ of the mats (ca. $1 \mathrm{~g}$ each) in triplicate, before and after the flood, were used for pigment extraction. Extraction of pigments was performed with icecooled $90 \%$ acetone after sonication and incubation at $-20^{\circ} \mathrm{C}$ for $24 \mathrm{~h}$. The supernatants were filtered through Acrodisc ${ }^{\circledR}$ CR $4 \mathrm{~mm}$ syringe filters of pore size $0.45 \mu \mathrm{m}$ (Pall Gelman Laboratory). The whole procedure was carried out on ice under dim light. The pigments were analyzed using reverse-phase HPLC that consisted of a Waters 996 photo diode array detector (PDA) and a Waters 2690 separation module following the EPA method 447.0 procedure (Arar 1997, version 1.0). We used a $125 \times 4.6 \mathrm{~mm}$ vertex column packed with Eurospher-100 C18 of $5 \mu \mathrm{m}$ particle size (Knauer). The pigments were identified by comparing the retention time and the spectrum with commercially available pigment standards (DHI Water and Environment, and Merck).

Acetylene reduction rates. Nitrogenase activity was estimated by the acteylene-reduction assay (Steward et al. 1967) in light, before and after flooding, using fresh mat samples. Directly after collection, triplicate samples, each $1 \mathrm{~cm}^{2}$, were excised from each of the mats using a sharp sterile scalpel. In the laboratory, the pieces of mat were placed individually into glass bottles of $10 \mathrm{ml}$ total volume; the bottles were then sealed with rubber stoppers and aluminium crimps. Ten percent of the headspace volume was replaced by acetylene, and the bottles were incubated for $10 \mathrm{~h}$ under in situ conditions at $35^{\circ} \mathrm{C}$ and a light intensity of $66900 \mathrm{~lx}$. The ethylene concentration was measured after $10 \mathrm{~h}$ by injecting $500 \mu \mathrm{l}$ from the headspace into a gas chromatograph (Shimadzu) equipped with a flame ionization detector (FID). Nitrogen was used as a carrier gas, and the following temperatures were set for the gas chromatography (GC): injector $100^{\circ} \mathrm{C}$, detector $120^{\circ} \mathrm{C}$, and column $100^{\circ} \mathrm{C}$. Calibration was performed using a range of 
different ethylene gas concentrations made by mixing pure ethylene with synthetic air. Acetylene reduction activity was expressed as $\mu \mathrm{mol}$ ethylene $\mathrm{m}^{-2} \mathrm{~h}^{-1}$.

Statistical analysis. Statistical analysis of ARISA fingerprints and calculation of bacterial richness were carried out using the PRIMER 6 software package (PRIMER-E). The consensus ARISA table containing samples by OTUs was used to calculate pairwise similarities among samples based on the Bray-Curtis similarity index, and the resulting matrix was examined for patterns in bacterial communities before and after the flood. Analysis of similarities (ANOSIM) was carried out to test for significant differences between microbial communities before and after the flood. ANOSIM produces a sample statistic $(R)$ which represents the degree of separation between test groups (Clarke 1993). A multivariate analysis of all sites was performed using multidimensional scaling (MDS) based on Bray-Curtis similarities. Ordination of the BrayCurtis similarities was performed using non-metric MDS, with 100 random restarts, and the results were plotted in 2 dimensions. Whole bacterial communities were also compared before and after the flood by calculating the Jaccard index of similarity and the Whittaker index of similarity as described in Hewson \& Fuhrman (2006). While the Jaccard index is metric, and considers only the presence/absence of OTUs, Bray-Curtis and Whittaker indices are based on comparison of the relative abundances of OTUs.

The effects of site and flooding on the distribution of pigments were analysed by multivariate analysis of variance (MANOVA). Data were log-transformed before testing to ensure that they were homoscedastic. Subsequently, univariate 2-way analysis of variance (ANOVA) was used to determine changes in individual
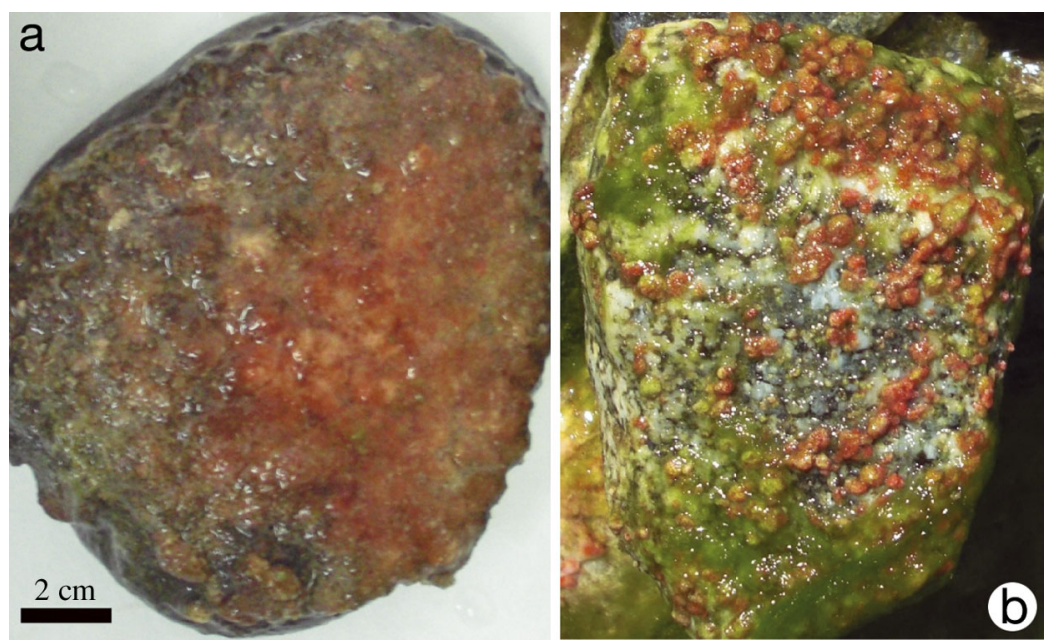

Fig. 1. Microbial mats on a stone surface from Wadi Al Khoud, Sultanate of Oman, collected from Site 3 in November 2008 and April 2009 (a) before flooding, and (b) after flooding. Small red granules in (b) are newly developed mats pigments. Similarly, the effects of site and flooding on acetylene reduction rates were tested using 2-way ANOVA. Tukey's test was used as a post hoc test where an overall ANOVA was significant. A value of $\mathrm{p}<0.05$ was taken to indicate significance.

\section{RESULTS}

\section{Physical and bacterial community changes}

Heavy rainfall in March 2009 resulted in an intense spate within the wadi. A total rainfall of $27.6 \mathrm{~mm}$, i.e. $30 \%$ of the average annual precipitation, was recorded at the closest monitoring site (Muscat International Airport). As the soil in the region is extremely rocky, or highly compacted, most of the rainfall translates into surface flow, resulting in a very strong flow. Erosion marks indicated that the flood had reached a height of $1.5 \mathrm{~m}$, and it took about $2 \mathrm{wk}$ for flows to return to base levels. The physical effects of flooding were most apparent at sites 1 to 4 , where heavy scouring had deepened and widened the channel. Analysis of phosphate and ammonium in the water samples before and after the flood showed that their concentrations were below detection limits at all times. The abundance of the floating alga Spirogyra increased remarkably after the flood and covered large areas of the stream, as assessed visually.

\section{Bacterial community changes}

Microbial mats had been removed from all sites, although remnants of the old mats still existed, but new patches of mats had started to grow over the surface of rocks (Fig. 1). The newly developed mats were red, and they formed small granules on the surface of rocks (Fig. 1). Direct microscopy of the mats before the flood showed that they harboured a variety of cyanobacterial morphotypes belonging to 11 genera: 4 coccoidal (Aphanocapsa, Aphanothece, Gloeocapsa and Chroococcus) and 7 filamentous (Calothrix, Oscillatoria, Spirulina, Leptolyngbya, Lyngbya, Schizothrix, Homoeothrix). After the flood, the heterocystous Calothrix spp. outcompeted other cyanobacterial populations and dominated all newly developed mats. Calothrix spp. is characterized by its tapering trichomes, with ellipsoidal or spherical heterocysts located at the base of the filaments or near points of false branching. 
Using the ARISA technique, we identified a total pool of 384 distinct OTUs (i.e. binned ARISA peaks) distributed among all mat samples before and after the flood (Fig. 2). Comparison of the richness of the OTUs in all mats before and after the flood showed that the total number of OTUs decreased after the flood in 6 out of the 12 studied mats, but remained similar or slightly increased in the other 6 (Fig. 2a). The average number of OTUs in the 12 mats before the flood was 119, with the highest in mats from Sites 4 and 6 (i.e 160 and 151, respectively) and 102 after the flood, with the highest in mats from Sites 2 and 6 (i.e. 131 and 139, respectively). The lowest number of OTUs was 73 for the mat from Site 1 before the flood, and 60 for the mat from Site 5 after the flood (Fig 2a). More than $74 \%$ of the OTUs detected before the flood were replaced by new ones after the flood. Using only information on the presence/absence of OTUs, fingerprints before and after the flood shared $0.28 \pm 0.04$ Jaccard index, but when relative abundances were compared, the 2 communities shared $0.38 \pm 0.17$ Whittaker index. Pairwise comparison of the presence/absence of OTUs showed only between 18 and 26\% shared OTUs among all mats, before and after the flood, with the highest average shared OTUs detected at Site 2 and the lowest at Site 3 (Fig. 2b). Multivariate analyses of ARISA profiles before and after the flood revealed that the structure of the bacterial community had changed and that each group formed a separate cluster with little overlap (ANOSIM, $R=0.49$, $\mathrm{p}<0.001$; see Fig. 4a).

\section{Pigment composition and distribution}

The concentrations of the detected pigments for every site ( 2 mats, each in triplicate) were averaged and compared among sites, as well as before and after the flood. Overall, the composition of pigments in the mats varied significantly with site (MANOVA, p = 0.009 ) and with flooding (MANOVA, $p=0.003$ ). There was also an interaction between the effects of site and flooding on composition (MANOVA, $p=0.001$ ). The patterns for individual pigments were analysed to determine the main sources of these effects. Chlorophyll a (chl a) was the most abundant pigment at all sites (Fig. 3). The biomass of phototrophs, as indicated by chl $a$, varied between locations, with Sites 1, 2 and 6 having the overall highest density and Sites 3, 4 and 5 having the lowest density (ANOVA, p $<0.0001$ ). There was, however, no effect of flooding on the concentration of chl a (Fig. 3). Chlorophyllid a, a known precursor of chl $a$, showed an increase after flooding at Sites 1, 2 and $6(p<0.001)$. Of the other pigments, scytonemin, a known UV sunscreen pigment in cyanobacteria (Fleming \& Castenholz 2007), showed the greatest variation with site-specific effects of flooding (ANOVA, p < 0.0001). Scytonemin was abundant at Sites 3 and 5 before flooding and was rare elsewhere (Fig. 3). After flooding, it became common in mats at Sites 2 and 6 but was greatly reduced elsewhere. Echinenone, a carotenoid present in cyanobacteria, did not exhibit significant differences before and after the flood (Fig. 3). The apparent increase after flooding at Site 2 was not statistically
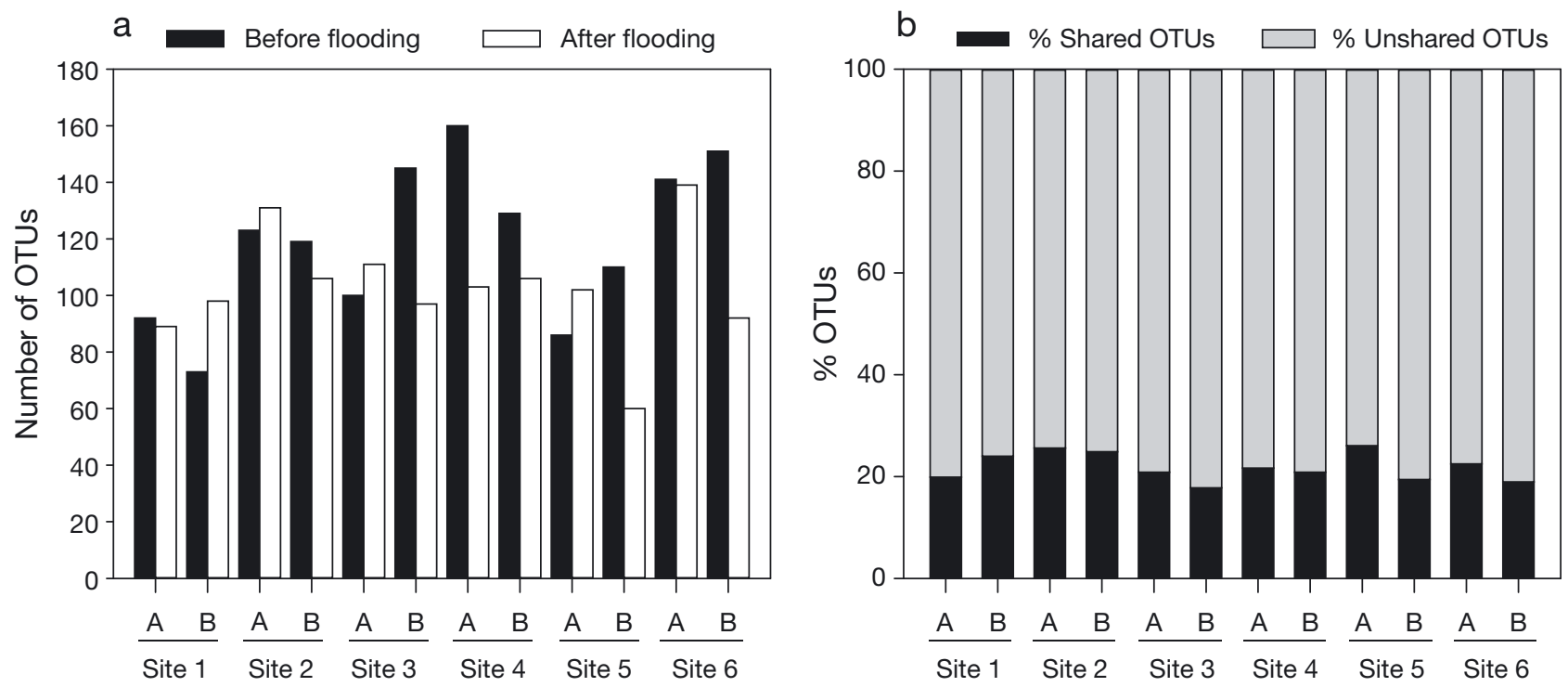

Fig. 2. (a) Number of operational taxonomic units (OTUs) obtained from automated rRNA intergenic spacer analysis (ARISA) profiles at each mat before and after flooding. (b) Percentage of OTUs shared and not shared in the replicate of the different mats before and after flooding. A and B refer to the duplicate mats from each of the 6 sampling sites 

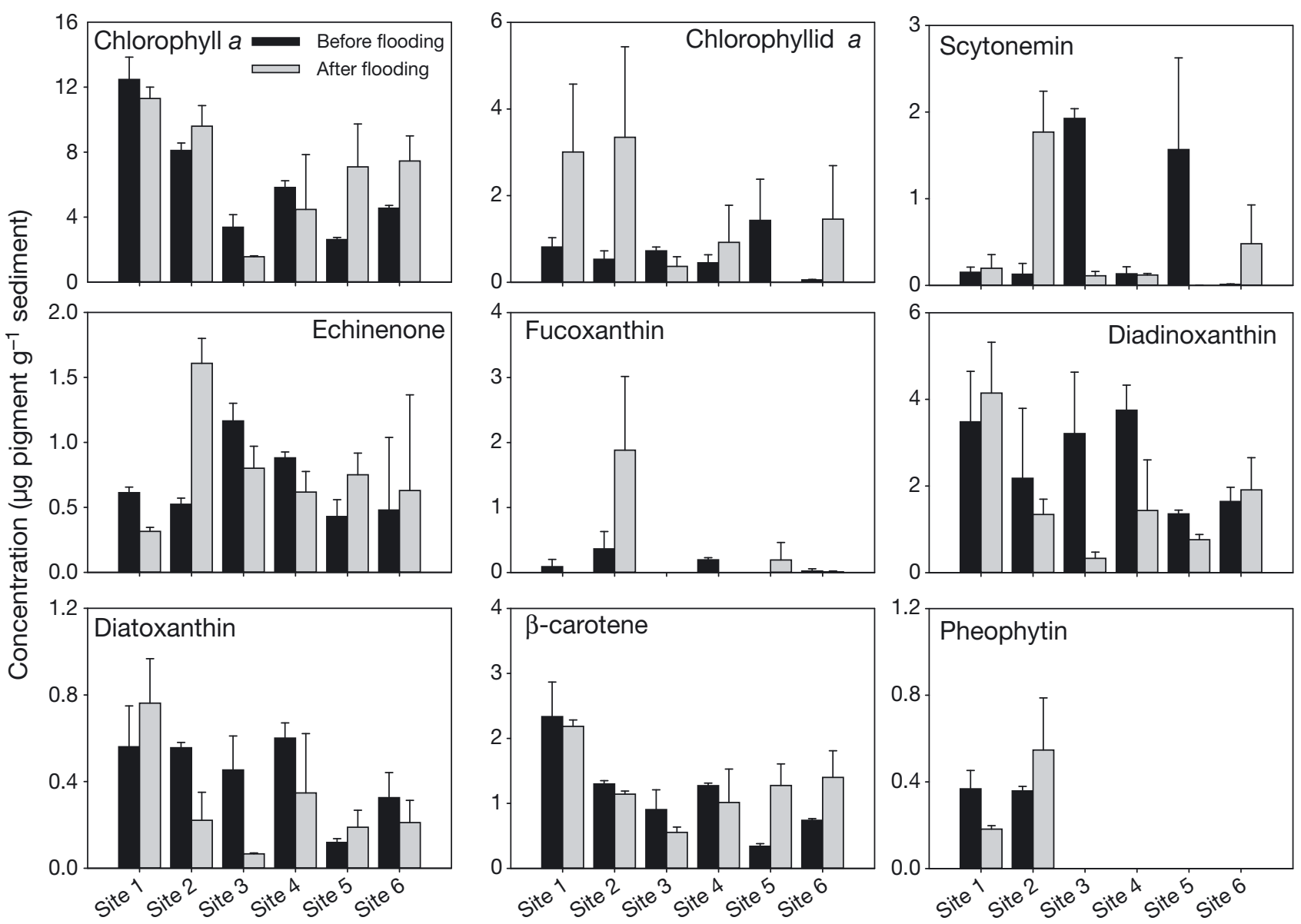

Fig. 3. Distribution of intracellular and extracellular pigments among the 6 studied sites of the Wadi Al Khoud stream before and after flooding. Concentrations shown represent the average values obtained from 2 mat samples per site, each analyzed in triplicate $(\mathrm{n}=6)$. Error bars represent standard deviation. Note that the scale for every pigment is different, and the highest concentrations were of chlorophyll $a$

significant $(p>0.05)$. Pigments that are indicative of diatoms, such as fucoxanthin, diadinoxanthin and diatoxanthin, were also detected. Fucoxanthin was initially found only in abundance at Site 2 but increased at Sites 2 and 5 after flooding (ANOVA, p = 0.04). Before flooding, diadinoxanthin was most abundant at Sites 1, 3 and 4 but lowest at Sites 5 and 6, and its concentration generally decreased after flooding (ANOVA, $p=0.035$ ), although the trend was variable (Fig. 3). The highest average concentration of diatoxanthin was at Sites 1 and 4, and the lowest at Sites 3, 5 and 6 (ANOVA, p = 0.008). Flooding had either increased (at 2 sites) or decreased (at 4 sites) the average concentrations of diatoxanthin (ANOVA, p = 0.035). Phaeophytin (chlorophyll lacking the central magnesium ion) was the least abundant pigment but varied between sites (ANOVA, p < 0.0001); it was highest at Sites 1 and 2 and barely detectable at the other sites. Finally, $\beta$-carotene, which is present mainly in cyanobacteria, varied significantly between sites (ANOVA, p < 0.0001), with mats at Site 1 having a significantly greater amount than elsewhere. After flooding, $\beta$-carotene remained more or less stable except for Sites 5 and 6, where a marked increase was observed (ANOVA, $\mathrm{p}=0.023$ ). Multivariate analyses of detected pigments supported the ARISA data and showed that the structure of the microbial community had changed after the flood (ANOSIM, $R=0.46$, p < 0.028; Fig. 4b).

\section{Nitrogenase activity}

The mats' average acetylene reduction rates (calculated from the rates of 2 mat samples at each site, each analyzed in triplicate) before the flood showed a decreasing pattern from Sites 1 to 6 , with average rates ranging between 3 and $18 \mathrm{nmol} \mathrm{C}_{2} \mathrm{H}_{2}$ reduced $\mathrm{m}^{-2} \mathrm{~h}^{-1}$ at Sites 1 to 4 , and undetectable rates at Sites 5 and 6 (Fig. 5). After the flood, the average rates at all sites 

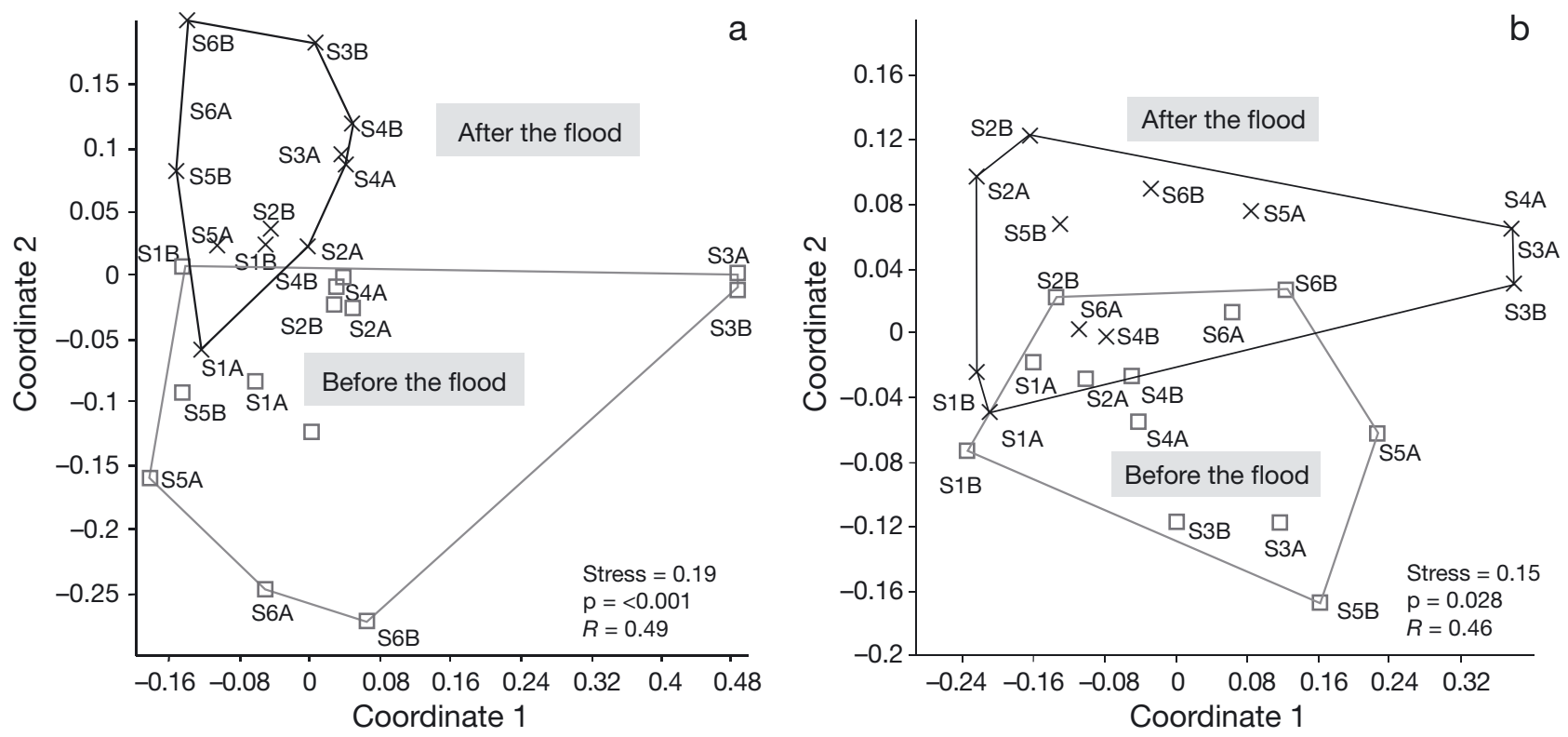

Fig. 4. Non-metric multidimensional scaling (NMDS) ordination (Bray-Curtis distance matrix) of (a) automated rRNA intergenic spacer analysis (ARISA) fingerprints (analysis of similarities [ANOSIM], $R=0.49, \mathrm{p}<0.001$ ) and (b) pigment distribution (ANOSIM, $R=0.46, \mathrm{p}<0.028$ ), from microbial mat samples before and after flooding. Sampling sites are designated by the letter $\mathrm{S}$ followed by the respective number (1 to 6), and the duplicate mat samples are labelled A and B

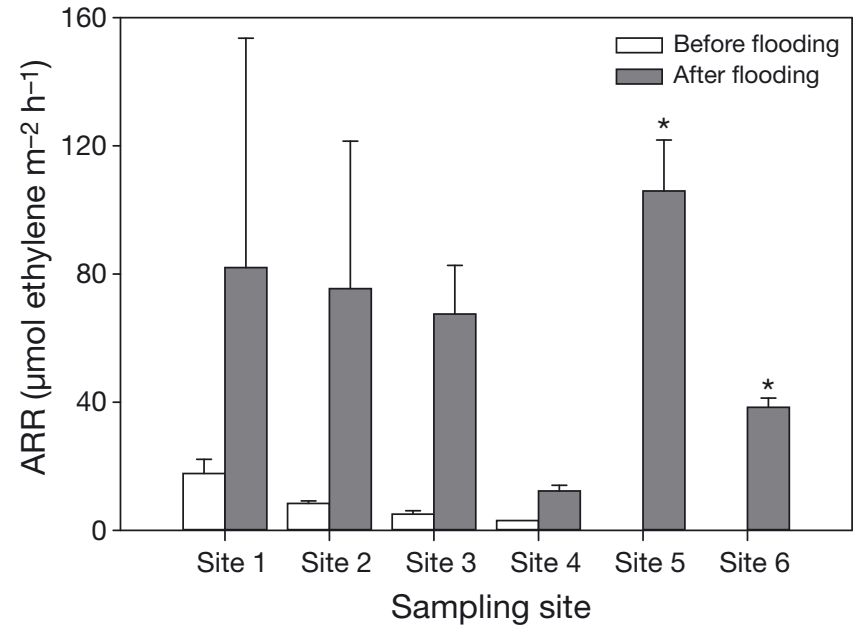

Fig. 5. Average acetylene reduction rates (ARR) of microbial mats from the 6 studied sites before and after flooding. Error bars represent standard deviation. Note the significant $\left({ }^{\star} \mathrm{p}<0.01\right)$ increase in ARR at Sites 5 and 6

increased; however, because of high variance among samples, the increase was significant only for Sites 5 and 6 (ANOVA, p < 0.01). In these sites, acetylene reduction rates markedly increased after flooding, where the highest rate was measured at Site 5 (i.e. 106 nmol $\mathrm{C}_{2} \mathrm{H}_{2}$ reduced $\mathrm{m}^{-2} \mathrm{~h}^{-1}$ ). There were no significant differences in acetylene reduction rates among the sites if the comparison was done for each event (before and after flooding) separately.

\section{DISCUSSION}

Flood-induced disturbance affected the community structure, pigment composition and nitrogenase activity of the desert stream's microbial mat communities. The microbial communities of the mats recovered relatively fast, and intact microbial mats were observed in less than 2 wk after the flood. Similar speedy post-flood recovery of the biota was also observed in other desert streams, such as Sycamore Creek, Arizona (Fisher et al. 1982, Peterson et al. 1994), although it took up to several years in some other cases (Bilby 1977, Siegfried \& Knight 1977). The flood-associated physical changes of the ecosystem, including increased rates of water flow, upwelling of sediment and the drifting of bacterial cells through scouring of rocks, resulted in the replacement of more than $74 \%$ of the ARISA OTUs. Although we recognize the difficulty in establishing a link between each OTU and its bacterial identity, visual observations, direct microscopy and pigment analysis suggest that some of the persistent OTUs in our mats could belong to phototrophic microorganisms (mainly cyanobacteria and diatoms). Previous studies have shown the occurrence of diatoms and cyanobacteria-affiliated OTUs in molecular analyses of complex microbial assemblages (Rappe et al. 1998, Zwart et al. 2002). In our mats, the heterocystous Calothrix spp. were microscopically observed to persist and dominate most mats after the flood. Phototrophs stick firmly to stone surfaces and withstand the shearing 
forces created by high water flows as a result of their filamentous structure and production of extracellular mucilage (Biggs \& Close 1989). Nevertheless, the loss of some populations cannot be completely excluded (Power \& Stewart 1987, Stevenson 1990, Yang et al. 2009), particularily when currents are very strong. Although previous studies showed a dramatic decline in the abundance of the benthic biomass of phototrophs (Power \& Stewart 1987, Stevenson 1990, Yang et al. 2009), the abundance of benthic phototrophic microorganisms in our mats did not change significantly, as assessed using chl a as a proxy. Moreover, the diatom-specific pigments - such as fucoxanthin, diatoxanthin and diadinoxanthin - did not show a consistent pattern after the flood. This could be due to variable levels of scouring at different sites depending on the site's position in the stream and/or to the speed of recovery and growth of phototrophic populations after the flood, which could be species dependent. The concentrations of the UV sunscreen pigment scytonemin, produced by the mat phototrophs after the flood, decreased at Sites 3 and 5, most likely because of the inundation and reduced exposure to direct sunlight. Scytonemin concentrations were shown to be higher in dry mats compared to inundated mats (Abed et al. 2008), and periodic desiccation was shown to induce scytonemin synthesis in cyanobacteria (Fleming \& Castenholz 2007). Unlike the benthic phototrophs, an increase in the green alga Spirogyra was triggered after flooding at most sites, an observation that is consistent with previous reports (Power \& Stewart 1987, Biggs \& Close 1989, Stevenson 1990). The stimulation of algal productivity has been shown to be due to the high loading of dissolved nutrients by the flood water and/or the reduction in grazing pressure by macroinvertebrates (Grimm \& Fisher 1986a, Hamilton \& Duthie 1987, Flinders \& Hart 2009).

The multivariate plots based on ARISA data and pigment distibution were congruent and supported a separation between the microbial community clusters before and after the flood. The newly developed microbial communities may contain opportunistic microorganisms that are normally present at low frequencies under natural conditions but overgrew others after the flood (Grimm \& Fisher 1986a). These autochthonous assemblages of taxa are important for microbial successions during the recovery of ecosystems following catastrophic impacts and were found to take over during eutrophication, pollution or dredging until normal, oligotrophic conditions are restored (Pearson \& Jones 1975, Abed \& Garcia-Pichel 2001). The replacement of more than $74 \%$ of the OTUs in each mat could be attributed to the differences between thick mature mats, containing aerobic and anaerobic layers of microorganisms, and the thin, recently developed mats, which are probably dominated by aerobic bacteria. While the community structure changed dramatically after the flood, the OTU richness decreased or remained unchanged in most cases, although it increased at a few locations. Bacterial species richness has been shown to follow a successional model in river biofilms (Jackson et al. 2001). According to this model, species richness increases during the early stages of bacterial succession as a result of increased microhabitats during biofilm development (Santegoeds et al. 1998) but then decreases when the biofilm becomes mature due to the competitive dominance of a few species (Jackson et al. 2001, Lyautey et al. 2005). When this model is applied to the 2 time points of our study, it becomes evident that the mats we studied are probably at different stages of development. The mats showing a decrease in their OTU richness after the flood are probably at the stage at which less-competitive species become subdominant and undetectable with ARISA, while those with increased OTUs are probably at the transitory period of maximum richness in the early stages of community development. The increase in microbial diversity in several mats could also be explained according to the intermediate disturbance hypothesis (Kneitel \& Perrault 2006). According to this hypothesis, disturbances that are neither too rare nor too frequent (in this case flooding) may not affect the resistant fraction of the original community but may promote the growth of those species that deal well with disturbance, thus promoting the coexistence of species and leading to increased biodiversity (Buckling et al. 2000, Johst \& Huth 2005). In our mats, Calothrix spp. clearly belonged to the pioneer species that could resist and cope well with the flood.

Nitrogenase activity increased after the flood, although the increase was statistically significant only in the case of Sites 5 and 6 . Our acetylene reduction rates in the stream mats were comparable to those measured in other freshwater and hypersaline mats (Grimm \& Petrone 1997, De Wit et al. 2005). The high variability in acetylene reduction rates after the flood among the triplicates of the remaining sites emphasized the high degree of heterogeneity of nitrogenfixing microorganisms, even on a single stone. Microbial mats, which freshly colonized sediments, were shown to exhibit higher rates of nitrogen fixation compared with established mats (Villbrandt et al. 1991). It is therefore reasonable to assume that our post-flood mats favoured OTUs capable of nitrogen fixation. We speculate that a large fraction of the measured increase in nitrogenase activity could be attributed to the heterocystous Calothrix spp., whose abundance apparently increased after the flood as assessed by direct microscopy. Calothrix spp. are widespread in 
flowing or standing waters such as shallow streams or tidal pools (Peterson et al. 1994, Grimm \& Petrone 1997) and was found to be an important late-successional component of the periphyton (Peterson et al. 1994, Grimm \& Petrone 1997). The growth of heterocystous cyanobacteria was found to be triggered under nitrogen-limiting conditions combined with low currents, high exposure to light and an increase in temperature (Bergmann \& Welch 1990, Peterson \& Grimm 1992, Peterson et al. 1994). The increased acetylene reduction rates after the flood suggest that the stream ecosystem became nitrogen limited. Previous studies have shown that nitrogen becomes abundant immediately after floods, but nitrogen concentrations decline rapidly as flood waters recede and succession occurs (Fisher et al. 1982, Grimm \& Petrone 1997). The low detectability of phosphorus and ammonium at our sites after the flood is congruent with these findings. The decline in nutrients immediately after the flood could be attributed to their rapid uptake by floating Spirogyra spp. (Hamilton \& Duthie 1987) and by the newly developed mats. Similar observations were reported in a subtropical east Australian estuary (Brunswick), where almost the complete dissolved inorganic nitrogen was removed by phytoplankton after the flood (Eyre \& Ferguson 2006). This is in accordance with the conceptual model proposed by Teissier et al. (2007), according to which young, thin and actively growing epilithic biofilms assimilate nitrogen from water at rates exceeding mineralization, and use it for growth, while thick biofilms mineralize nitrogen at a rate higher than the uptake rate (Teissier et al. 2007). Nitrogen limitation and $\mathrm{N}_{2}$ fixation can be separated in space, and factors controlling $\mathrm{N}_{2}$ fixation rates can significantly vary among different sites as a consequence of stream heterogeneity (Vitousek \& Howarth 1991).

Our study showed that the regrowth and recovery of function (i.e. nitrogen fixation) in this system occurred rapidly (in $<2 \mathrm{wk}$ ) following intense flooding. Although desert streams are extremely heterogeneous environments, all representative mats in this study showed more than $74 \%$ replacement of native microorganisms, estimated as OTUs and stable or increased nitrogenfixation rates after flooding. Future studies should consider both greater coverage of the stream, spatially and temporally, and higher levels of replication in sampling in order to gain more insight into the overall response of the stream communities to the disturbances caused by flooding.

Acknowledgements. We thank A. Atta for his help in measuring acetylene reduction rates. We also thank Sultan Qaboos University (SQU) for granting R.M.M.A. a research stay, and the Max-Planck Institute for Marine Microbiology (MPIMM), Bremen, Germany, for providing research facilities and in- kind contribution during that stay. This research is funded from an internal grant from SQU (grant No. IG/SCI/BIOL/ 09/01).

\section{LITERATURE CITED}

Abed RMM, Garcia-Pichel F (2001) Long-term compositional changes after transplant in a microbial mat cyanobacterial community revealed using a polyphasic approach. Environ Microbiol 3:53-62

Abed RMM, Kohls K, Schoon R, Scherf AK and others (2008) Lipid biomarkers, pigments and cyanobacterial diversity of microbial mats across intertidal flats of the arid coast of the Arabian Gulf (Abu Dhabi, UAE). FEMS Microbiol Ecol 65:449-462

Arar EJ (1997) Determination of chlorophylls $a$ and $b$ and identification of other pigments of interest in marine and freshwater algae using high performance liquid chromatography with visible wavelength detection. Method 447.0, Environmental Protection Agency, Cincinnati, OH

Augspurger C, Karwautz C, Mußmann M, Daims H, Battin TJ (2010) Drivers of bacterial colonization patterns in stream biofilms. FEMS Microbiol Ecol 72:47-57

Bergmann MA, Welch HE (1990) Nitrogen fixation by epilithic periphyton in small arctic lakes in response to experimental nitrogen and phosphorus fertilization. Can J Fish Aquat Sci 47:1545-1550

> Besemer K, Singer G, Hödl I, Battin T (2009) Bacterial community composition of stream biofilms in spatially variable-flow environments. Appl Environ Microbiol 75: 7189-7195

Biggs BJF, Close ME (1989) Periphyton biomass dynamics in gravel bed rivers: the relative effects of flows and nutrients. Freshw Biol 22:209-231

- Bilby R (1977) Effects of a spate on the macrophyte vegetation of a stream pool. Hydrobiologia 56:109-112

Böer SI, Hedtkamp SIC, van Beusekom JEE , Fuhrman JA, Boetius A, Ramette A (2009) Time- and sediment depthrelated variations in bacterial diversity and community structure in subtidal sands. ISME J 3:780-791

Boulêtreau S, Sellali M, Elosegi A, Nicaise Y and others (2010) Temporal dynamics of river biofilm in constant flows: a case study in a riverside laboratory flume. Int Rev Hydrobiol 95:156-170

Buckling A, Kassen R, Bell G, Rainey PB (2000) Disturbance and diversity in experimental microcosms. Nature 408: 961-964

Bunn SE, Balcombe SR, Davies PM, Fellows CS, McKenzieSmith FJ (2006a) Productivity and aquatic food webs of desert river ecosystems. In: Kingsford RT (ed) Changeable, changed, changing: the ecology of desert rivers. Cambridge University Press, Cambridge, p 76-99

> Bunn SE, Thoms MC, Hamilton SK, Capon SJ (2006b) Flow variability in dryland rivers: boom, bust and the bits in between. River Res Appl 22:179-186

> Cardinale M, Brusetti L, Quatrini P, Borin S and others (2004) Comparison of different primer sets for use in automated intergenic spacer analysis of complex bacterial communities. Appl Environ Microbiol 70:6147-6156

> Clarke KR (1993) Non-parametric multivariate analysis of changes in community structure. Aust J Ecol 18:117-143

> De Wit R, Falcon LI, Charpy-Roubaud C (2005) Heterotrophic dinitrogen fixation (acetylene reduction) in phosphatefertilised Microcoleus chthonoplastes microbial mat from the hypersaline inland lake 'Ia Salada de Chiprana' (NE Spain). Hydrobiologia 534:245-253 
Elser JJ, Marzolf ER, Goldman CR (1990) Phosphorus and nitrogen limitation of phytoplankton growth in the freshwaters of North America: a review and critique of experimental enrichments. Can J Fish Aquat Sci 47:1468-1477

Eyre BD, Ferguson AJP (2006) Impact of flood event on benthic and pelagic coupling in a sub-tropical east Australian estuary (Brunswick). Estuar Coast Shelf Sci 66:111-122

Fischer M, Membery DA (1998) Climate. In: Ghazanfar SA, Fisher $M$ (eds) Vegetation of the Arabian Peninsula. Kluwer Academic Publishers, Dordrecht, p 5-38

Fisher SG, Gary LJ, Grimm NB, Busch DE (1982) Temporal succession in a desert stream ecosystem following flash flooding. Ecol Monogr 52:93-110

Fleming ED, Castenholz RW (2007) Effects of periodic desiccation on the synthesis of the UV-screening compound, scytonemin, in cyanobacteria. Environ Microbiol 9: 1448-1488

Flinders CA, Hart DD (2009) Effects of pulsed flow on nuisance periphyton growth in rivers: a mesocosm study. River Res Appl 25:1320-1330

Grimm NB, Fisher SG (1986a) Nitrogen limitation in a Sonoran Desert stream. J North Am Benthol Soc 5:2-15

Grimm NB, Fisher SG (1986b) Nitrogen limitation potential of Arizona streams and rivers. J Ariz Nev Acad Sci 21:31-43

> Grimm NB, Petrone KC (1997) Nitrogen fixation in a desert stream ecosystem. Biogeochemistry 37:33-61

Hamilton PB, Duthie HC (1987) Relationship between algal drift, discharge and stream order in a boreal forest watershed. Arch Hydrobiol 110:275-289

> Hewson I, Fuhrman JA (2006) Improved strategy for comparing microbial assemblage fingerprints. Microb Ecol 51: $147-153$

Jackson CR, Churchill PF, Roden EE (2001) Successional changes in bacterial assemblage structure during epilithic biofilm development. Ecology 82:555-566

Johst K, Huth A (2005) Testing the intermediate disturbance hypothesis: when will there be two peaks of diversity? Biodivers Res 11:111-120

Kneitel JM, Perrault D (2006) Disturbance-induced changes in community composition increase species invasion success. Community Ecol 7:245-252

Lyautey E, Jackson CR, Cayrou J, Rols JL, Garabetian F (2005) Bacterial community succession in natural river biofilm assemblages. Microb Ecol 50:589-601

McDiffett WF, Beidler AW, Dominick TF, McCrea KD (1989) Nutrient concentration-stream discharge relationships during storm events in a first-order stream. Hydrobiologia 179:97-102

Ormerod SJ, Dobson M, Hildrew AG, Townsend CR (2010)

Editorial responsibility: Rutger de Wit, Montpellier, France
Multiple stressors in freshwater ecosystems. Freshw Biol 55(Suppl 1):1-4

Pearson RG, Jones NV (1975) The effect of dredging operations on the benthic community of a chalk stream. Biol Conserv 8:273-278

Peterson CG, Grimm NB (1992) Temporal variation in enrichment effects during periphyton succession in a nitrogenlimited desert stream ecosystem. J North Am Benthol Soc 11:20-36

Peterson CG, Weibel AC, Grimm NB, Fisher SG (1994) Mechanisms of benthic algal recovery following spates: comparison of stimulated and natural events. Oecologia 98: $280-290$

Power ME, Stewart AJ (1987) Disturbance and recovery of an algal assemblage following flooding in an Oklahoma Stream. Am Midl Nat 117:333-345

Rappe MS, Suzuki MT, Vergin KL, Giovannoni SJ (1998) Phylogenetic diversity of ultraplankton plastid small-subunit rRNA genes recovered in environmental nucleic acid samples from the Pacific and Atlantic coasts of the United States. Appl Environ Microbiol 64:294-303

Santegoeds CM, Ferdelman TG, Muyzer G, de Beer D (1998) Structural and functional dynamics of sulfate-reducing populations in bacterial biofilms. Appl Environ Microbiol 64:3731-3739

Siegfried CA, Knight AW (1977) The effects of washout in a Sierra Foothill stream. Am Midl Nat 98:200-207

Stevenson RJ (1990) Benthic algal community dynamics in a stream during and after a spate. J North Am Benthol Soc 9:277-288

Steward WDP, Fitzgerald GP, Burris RH (1967) In situ studies of $\mathrm{N}_{2}$ fixation using acetylene reduction technique. Proc Natl Acad Sci USA 92:9358-9362

Teissier S, Torre M, Delmas F, Carabetian F (2007) Detailing biogeochemical $\mathrm{N}$ budgets in riverine epilithic biofilms. J North Am Benthol Soc 26:178-190

Villbrandt M, Krumbein WE, Stahl LJ (1991) Diurnal and seasonal variations of nitrogen fixation and photosynthesis in cyanobacterial mats. Plant Soil 137:13-16

Vitousek PM, Howarth RW (1991) Nitrogen limitation on land and in the sea: How can it occur? Biogeochemistry 13: $87-115$

Yang GY, Tang T, Dudgeon D (2009) Spatial and seasonal variations in benthic algal assemblages in streams in monsoonal Hong Kong. Hydrobiologia 632:189-200

Zwart G, Crump BC, Kamst-van Agterveld MP, Hagen F, Han SK (2002) Typical freshwater bacteria: an analysis of available 16S rDNA gene sequences from plankton of lakes and rivers. Aquat Microb Ecol 28:141-155

Submitted: July 12, 2010; Accepted: February 1, 2011 Proofs received from author(s): May 2, 2011 